\title{
TIẾP CậN KHÁI NIỆM VỀ MặT PUASIGEOID
}

\author{
PGS. TSKH. HÀ MINH HOÀ \\ Viện Khoa học đo đạc và bản đồ
}

Lời nói đầu:

Molodenskii M.X. đưa ra mặt Quasigeoid để biểu diễn độ cao chuẩn từ mặt vật lý của Quả đất theo đường vuông góc với mặt Ellipsoid. Tuy nhiên trong các tài liệu về Trắc địa cao cấp giải thich về mặt này rất khác nhau, thậm tri coi mặt này chỉ là sản phẩm của quá trinh xác định độ cao chuẩn của các điểm trên mặt vật lý của Quả đất. Báo cáo khoa học này sẽ chỉ ra rằng mặt Quasigeoid là hinh ảnh của mặt Geoid với thế thực $W=W_{0}$ trong trường trọng lực chuẩn của Quả đất và liên hệ chặt chẽ với mặt Geoid này. Tư đây chúng ta có thể xem xét quan hệ của mặt Quasigeoid với mặt Geoid trên các biển và đại dương, và cần phải xem xét lại việc coi độ cao chuẩn bằng 0 trên các biển và đại dương. Các kết quả nghiên cứu trong bài báo này sẽ xác định cơ sở khoa học cho việc hoàn thiện hệ độ cao quốc gia.

\section{1. Đặt vấn đề}

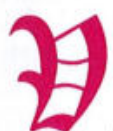
iệc phát triển nhanh chóng các ứng dụng của công nghệ GPS cùng với các kết quả nghiên cứu xác định thế chuẩn $\cup_{0}$ trên mặt của một số ellipsoid nhờ phương pháp đo cao vệ tinh (Altimetry) và sự tăng nhanh các kết quả đo đạc trọng lực chi tiết trên các lục địa và biển ở các khu vực khác nhau đã thúc đẩy nhanh cả công tác xác định độ cao Geoid (hoặc độ cao QuasiGeoid) độ chính xác cao ở các nước với mục đích xác định độ cao chính (hoặc độ cao chuẩn) bằng công nghệ GPS, lẫn công tác hoàn thiện hệ thống độ cao quốc gia ở nhiều nước trên thế giới.

Việc hoàn thiện hệ thống độ cao quốc gia nhằm đảm bảo sự thống nhất các kết quả đo cao của các điểm trển lục địa, độ sâu địa hình đáy biển trong hệ độ cao thống nhất trên phạm vi một quốc gia hoặc rộng lớn hơn. Công việc này đòi hỏi phảl xác định một cách khoa học mặt khởi tính cho hệ độ cao hiện đại.

Các kết quả nghiên cứu hiện đại trên thế giới, như đã nêu trong tài liệu [2], đã chỉ ra rằng mặt nước biển ở các khu vực trên thế giới không trùng nhau. Do đó mặt nước biển trung bình trên các biển và đại dương không phải là mặt đẳng thế của trường trọng lực thực. Định nghĩa Gauss - Bexel cho rằng mặt Geoid trùng với mặt nước biển trung binh trên các biển và đại dương (là mặt vật chất tồn tại trên bề mặt Quả đất) không còn là cơ sở khoá học để triển khai xây dựng hệ độ cao hiện đại mà dựa vào đó có thể thống nhất việc xác định độ cao trên đất liền và độ sâu địa hình đáy biển, địa hình mặt biển trong phạm vi một quốc gia hoặc một khu vực rộng hơn. Việc xác định mặt khởi tính cho hệ độ cao hiện đại đáp ứng được các yêu cầu thống nhất việc xác định độ cao trên đất liền và độ sâu địa hình đáy biển, địa hình mặt biển trong phạm vi một quốc gia hoặc một khu vực rộng hơn hiện đang là vấn đề khoa học - kỹ thuật đòi hỏi các nhà khoa học trắc địa phảl đâu tư nghiên cứu giải quyết nhằm hoàn thiện hệ thống độ cao quốc gia ở nhiều nước trên thế giới. Để giảl quyết vấn đề này đòi hỏi phảl làm sâu sắc thêm lý thuyết hệ độ cao chuẩn của Molodenxkii M.X.

Trên hình 1 dưới đây, $M$ là điểm trên mặt vật lý của Quả đất, mặt Geoid với thế thực

Người phản biện: GS. TSKH. Phạm Hoàng Lân 


\section{Mghiên cuíu - Cíng dụng}

$W=W_{0}$ đi qua điểm gốc $O$ của hệ độ cao, thế chuẩn của mặt Ellipsoid $U=U_{0}$, mặt Geoid với thế thực $W=W_{M}$ đi qua điểm $M$.

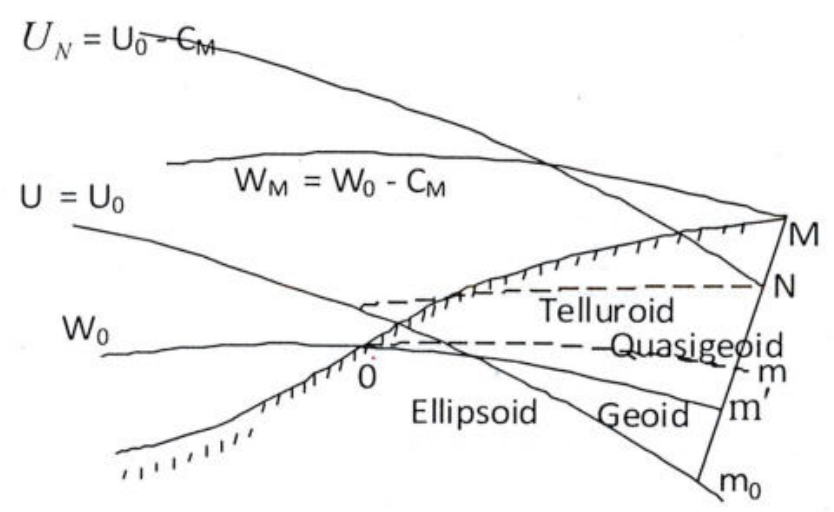

Hinh 1. Quan hệ giữa các mặt trong lý thuyết hệ độ cao

Từ điểm $\mathrm{M}$ dựng đường $\mathrm{Mm}_{0}$ vuông góc với mặt Ellipsoid. Theo lý thuyết hệ độ cao của Molodenxkii $\mathrm{M}$.X. (cách tiếp cận thứ nhất), nếu từ mặt Ellipsoid theo đường $\mathrm{m}_{0} \mathrm{M}$ dựng đoạn $\mathrm{m}_{0} \mathrm{~N}$ bằng độ cao chuẩn $H_{M}^{\gamma}$ thì điểm $\mathrm{N}$ nằm trên mặt Telluroid và có thế chuẩn $\mathrm{U}=\mathrm{U}_{\mathrm{N}}$, đoạn NM được gọi là dị thường độ cao và được ký hiệu là $\zeta_{M}$.

Đại lượng địa thế năng $C_{M}$ được xác định theo công thức:

$$
C_{M}=W_{0}-W_{M}=U_{0}-U_{N},
$$

và được gọi là điều kiện Molodenskii M.X.

Dựa theo điều kiện (1) độ cao chuẩn $H_{M}^{\gamma}$ và dị thường độ cao $\zeta_{M}$ được xác định theo các công thức sau:

$$
\begin{aligned}
H_{M}^{\gamma} & =\frac{C_{M}}{\gamma_{m}}=\frac{W_{0}-W_{M}}{\gamma_{m}}=\frac{U_{0}-U_{N}}{\gamma_{m}}, \\
\zeta_{M} & =\frac{U_{N}-U_{M}}{\gamma_{m}},
\end{aligned}
$$

ở đây $\gamma_{m}$ - giá trị trung bình của lực trọng trường chuẩn trên đoạn $\mathrm{Mm}_{0}, \mathrm{U}_{\mathrm{M}}$ - thế chuẩn của điểm $\mathrm{M}$.

Dựa trên điều kiện (1) và công thức (3) suy ra công thức xác định dị thường độ cao $\zeta_{M}$ dựa vào thế nhiễu $T_{M}=W_{M}-U_{M}$ tại điểm $M$ trên mặt vật lý của Quả đất:

$$
\begin{aligned}
& \zeta=-\frac{U_{M}-U_{N}}{\gamma_{m}}=-\frac{U_{M}-\left(U_{0}-C_{M}\right)}{\gamma_{m}}=-\frac{U_{M}-U_{0}+W_{0}-W_{M}}{\gamma_{m}}= \\
& =\frac{\left(W_{M}-U_{M}\right)}{\gamma_{m}}+\frac{U_{0}-W_{0}}{\gamma_{m}}=\frac{T_{M}}{\gamma_{m}}+\frac{U_{0}-W_{0}}{\gamma_{m}}=\frac{T_{M}}{\gamma_{m}}+\bar{\zeta}_{0},
\end{aligned}
$$

Công thức (4) là cơ sở để xác định dị thường độ cao dựa trên các kết quả đo trọng lực 


\section{Mghiên cuíu - Uíng dụng}

chi tiết trên mặt vật lý của Quả đất. Theo cách tiếp cận thứ nhất của Molodenxkii M.X. chúng ta sẽ phải làm rõ hai vấn đề: Nếu độ cao chuẩn được tính từ mặt Ellipsoid thì việc bắt đầu thực hiện đo thuỷ chuẩn từ mặt Ellipsoid sẽ được thực hiện như thế nào và thế thực $W=W_{0}$ trong công thức (1) có ý nghĩa như thế nào?. Các vấn đề trên không đơn giản để giải quyết.

Chúng ta xem xét cách tiếp cận thứ hai của Molodenxkii M.X.: tữ điểm $\mathrm{M}$ trên mặt vật lý của Quả đất (xem hình 1) theo đường vuông góc với mặt Ellipsoid $\mathrm{Mm}_{0}$ dựng đoạn $\mathrm{Mm}$ bằng độ cao chuẩn $H_{M}^{\gamma}$ Quỹ tích của điểm $\mathrm{m}$ được xác định bằng cách nêu trên nằm trên một mặt được gọi là Quasigeoid. Khi đó đoạn $\mathrm{mm}_{0}$ bằng dị thường độ cao $\zeta_{M}$. và được gọi là độ cao Quasigeoid. Như vậy dị thường độ cao và độ cao Quasigeoid có giá trị bằng nhau, nhưng có ý nghĩa khác nhau. Chúng ta có thể thấy rằng mặt Quasigeoid là mặt khởi tính cho hệ độ cao chuẩn và đi qua điểm gốc của hệ độ cao, thêm vào đó điểm gốc độ cao nằm trên mặt Geoid với thể thực $W=W_{0}$. Do đó theo cách tiếp cận thứ hai của Molodenxkii M.X. chúng ta không gặp hai vấn đề đã nêu ở trên đối với cách tiếp cận thứ nhất. Bài báo khoa học này sẽ sử dụng cách tiếp cận thứ hai nêu trên để luận giải các vấn đề khoa học được đặt ra.

Tồn tại các câu hỏi: mặt Quasigeoid thực chất có tính chất như thế nào và được xác định như thế nào? Trong các tài liệu trắc địa cao cấp có các giải thích khác nhau về mặt Quasigeoid:

- Mặt Quasigeoid không phải là mặt đẳng thế [7, 8];

- Mặt QuasiGeoid trùng với mặt Geoid $W=W_{0}$ trên các biển và đại dương và rất gần với mặt Geoid này trên các lục địa $[5,6,9]$;

- Độ cao chuẩn bằng 0 trên các biển và đại dương [5], tức mặt Quasigeoid trùng với mặt nước biển trung binh (mặt địa hình biển) và mặt nước biển trung bình trùng với mặt Geoid trên các biển và đại dương.

Vậy rõ ràng rằng muốn hoàn thiện hệ thống hệ độ cao chuẩn quốc gia chúng ta phải có câu trả lời khoa học cho các câu hỏi nêu trên và xem xét lại các cách giải thích nêu trên dựa trên các kết quả nghiên cứu hiện đại. Việc đầu tiên phải làm là làm rõ khái niệm về mặt Quasigeoid.

Như đã nêu ở trên, mặt nước biển trung bình trên các biển và đại dương không trùng với mặt Geoid. Do đó việc sử dụng mặt nước biển trung bình làm mặt khởi tính cho hệ độ cao không có cơ sở khoa học chặt chẽ. Vấn đề tiếp theo là khái niệm về mặt Geoid. Trong tài liệu [4], TS. Ogorodova L.V. hoàn toàn đủng đắn khi chỉ ra rằng xuất phát từ các quan điểm không có mặt Geoid duy nhất trên Quả đất, Geoid là mặt đẳng thế bất kỳ của trường trọng lực thực của Quả đất cắt mặt vật lý của Quả đất và trên Quả đất có vô số các mặt Geoid, các mặt Geoid đều đặc trưng cho hình dạng của bề mặt chung của Quả đất, Molodenskii $M . X$. đã xây dựng Lý thuyết hệ độ cao chuẩn mà theo đó độ cao chuẩn của một điểm $\mathrm{M}$ trên mặt vật lý của Quả đất được xác định dựa trên mặt Geoid (mặt đẳng thế thực) đi qua điểm $\mathrm{M}$, tức giải quyết vấn đề Stokes trên mặt Geoid đi qua điểm $\mathrm{M}$ trên mặt vật lý của Quả đất, chứ không phải trên mặt Geoid với thế thực $W=W_{0}$ đi qua điểm gốc 0 của hệ độ cao. Do đó định nghĩa được cho trong tài liệu [6]: Mặt Geoid là mặt đẳng thế gần với mặt nước biển trung bình không nhiễu trên các biển và đại dương, và mặt Geoid là mặt đẳng thế của 


\section{Mghiên cuíu - Oíng dụng}

lực trọng trường thực của Qủa đất với thế thực $W=W_{0}$ đi qua điểm gốc độ cao, với quan điểm hiện đại chỉ ám chỉ một mặt Geoid gần với mặt nước biển trung bình không nhiễu trên các biển và đại dương và được sử dụng để xây dựng hệ độ cao quốc gia. Tất nhiên mặt Geoid này cũng đặc trưng cho hình dạng của bề mặt chung của Quả đất.

Từ điều kiện (1) chúng ta có các đẳng thức:

$$
\begin{aligned}
& U_{N}=W_{M}-\left(W_{0}-U_{0}\right), \\
& U_{0}=W_{0}-\left(W_{0}-U_{0}\right) .
\end{aligned}
$$

Dựa trên hai đẳng thức trên, trong tài liệu [4] đã đồng nhất các khái niệm về dị thường độ cao và độ cao Geoid và coi chúng là đoạn trên đường vuông góc với mặt Ellipsoid giữa các điểm mà thế chuẩn $U$ tại một điểm khác thế thực $W$ tại điểm kia một đại lượng hằng số $\left(\mathrm{W}_{0}-\mathrm{U}_{0}\right)$. Việc đồng nhất này gây lẫn lộn giữa các khái niệm về dị thường độ cao và độ cao Geoid và làm cho khái niêm về mặt Quasigeoid càng trở nên bất định. Trong tài liệu [4] việc khẳng định mặt Quasigeoid chứa các thông tin về tất cả các Geoid (các mặt đẳng thế thực cắt mặt vật lỷ của Quả đất) và hoà trộn chúng thành một là đúng đắn. Tuy nhiên khi khẳng định để xác định độ cao không cần xây dựng mặt Quasigeoid thì chỉ đúng một nửa, bởi vì chúng ta vẫn phải trả lời các câu hỏi: độ cao chuẩn bắt đầu được tính từ đâu?. Nếu xây dựng hệ độ cao chuẩn đảm bảo thống nhất việc xác định độ cao trên đất liền và đô sâu đia hình đáy biển, địa hình mặt biển trong pham vi một quốc gia hoặc một khu vực rộng hơn thì phải dựa vào mặt khởi tính nào? Mặt Quasigeoid liên hệ với mặt Geoid với thế thực $W=W_{0}$ như thế nào?

Trong bài báo khoa học này sẽ làm rõ khái niệm về mặt Quasigeoid để giải đáp các câu hỏi nêu trên.

\section{Giải quyết các vấn đề}

Chúng ta thừa nhận rằng trên Quả đất có vô số mặt Geoid (mặt đẳng thế thực cắt mặt vật lý của Quả đất) và đúng như trong tài liệu [4] đã chứng minh rằng các mặt Geoid này đều đặc trưng cho hình dạng chung của Quả đất. Khi thay đổi độ cao so với mực nước biển sự thay đổi của dị thường độ cao được định nghĩa theo công thức (4) cũng chỉ đạt đến đại lượng một vài mét. Trong tài liệu [4] với giá trị trung bình của dị thường trọng lực của Quả đất ở mức $40 \mathrm{mGal}$, đối với mặt Geoid Brilliuzn đi qua đỉnh núi cao nhất thế giới (ở độ cao $10 \mathrm{~km}$ so với mực nước biển), sự thay đổi của dị thường độ cao (khi độ cao thay đổi từ mực nước biển đi một đại lượng $10 \mathrm{~km}$ ) chỉ ở mức $1,6 \mathrm{~m}$. Do đó để nghiên cứu hình dạng của Quả đất chúng ta có thể sử dụng mặt Geoid bất kỳ.

Tuy nhiên để xây dựng hệ độ cao chúng ta phải sử dụng một mặt Geoid nào đó với thế thực $\mathrm{W}=\mathrm{W}_{0}$ gần với mặt nước biển trung bình. Chỉ như vậy chúng ta mới xác định được điểu kiện (1) cuả Molodenskii M.X. trong việc xây dựng hệ độ cao chuẩn. Chính đây là vấn đề cần phải phân biệt rõ giữa Lý thuyết hệ độ cao và Lý thuyết hình dạng của Quả đất, mà theo đó khái niệm về Geoid trong Lý thuyết hình dạng của Quả đất rộng hơn so với Lý thuyết hệ độ cao, mặc dù hai lý thuyết này quan hệ chặt chẽ với nhau.

Chúng ta thừa nhận rằng mặt Geoid theo định nghĩa trong tài liệu [6] nêu trên cũng được sử dụng để nghiên cứu hình dạng của Quả đất, tuy nhiên nó khổng phải là duy nhất. Khi thừa nhận tồn tại nhiều mặt Geoid là các mặt cắt mặt vật lý của Quả đất, kể cả mặt Geoid 


\section{Mghiên caíu - Oíng dụng}

là mặt đẳng thế gần với mặt nước biển trung bình không nhiễu trên các biển và đại dương, và có thế thực $W=W_{0}$ đi qua điểm gốc độ cao thì mới hiểu rõ được lý thuyết hệ độ cao chuẩn của Molodenskii M.X..

Việc xác định mặt Geoid là mặt đẳng thế gần với mặt nước biển trung bình không nhiễu trên các biển, đại dương và có thế thực $W=W_{0}$ đi qua điểm gốc độ cao liên quan đến việc giải quyết vấn đề Stokes mà từ đây chúng ta đi đến lý thuyết hệ độ cao chính với các khái niệm về độ cao chính $H^{z}$ và độ cao Geoid $\bar{\zeta}$. Chúng ta biết rằng việc xác định mặt Geoid nêu trên cùng với việc xác định độ cao chính và độ cao Geoid đều được thực hiện trong trường trọng lực thực của Quả đất. Trong các tài liệu về Trắc địa cao cấp, ví dụ [6], trong trường trọng lực thực của Quả đất độ cao chính $H^{y}$ là đoạn m'M trên hình 1 và được xác định theo công thức:

$$
H_{M}^{g}=\frac{W_{0}-W_{M}}{g_{m}},
$$

ở đây $\mathrm{g}_{\mathrm{m}}$ - giá trị trung bình của gia tốc lực trọng trường trên đoạn m'M.

Do không biết được cấu tạo và sự phân bố vật chất bên trong của Quả đất, nên chúng ta không xác định được đại lượng $\mathrm{g}_{\mathrm{m}}$, tức không xác định được độ cao chính tữ các kết quả đo thuỷ chuẩn trên mặt vật lý của Quả đất. Điều này đều được khẳng định trong các tài liệu về Trắc địa cao cấp và giải thích sự không phổ biến của hệ độ cao chinh trong thực tế. Tư nhiên trong các tài liệu này không trình bày rõ phương pháp tính độ cao Geoid trong trường trọng lực thực của Quả đất. Chính vì vậy có sự nhầm lẫn trong tài liệu [4] khi đồng nhất các khái niệm về độ cao Geoid và dị thường độ cao và coi chúng đều là đoạn trên đường vuông góc với mặt Ellipsoid giữa các điểm mà thế chuẩn $U$ tại một điểm khác thế thực $W$ tại điểm kia một đại lượng hằng số. Sự nhầm lẫn nằm ở chỗ là chúng ta không thể sử dụng đồng thời cả thế chuẩn $U$ tại một điểm lẫn thế thực $W$ tại điểm khác để tính toán cả độ cao Geoid lẫn dị thường độ cao giữa các điểm này, tức không thể "trộn lẫn" trường trọng lực thực của Quả đất và trường trọng lực chuẩn của Quả đất để giải quyết bài toán xác định độ cao Geoid và dị thường độ cao. Chúng ta sẽ giải thích vấn đề này. Thật vậy, mặt Ellipsoid là mặt đẳng thế chuẩn với thế chuẩn $U=\cup_{0}$ là mặt khởi tính để tính thế chuẩn $U$ (thế lý thuyết) ở các điểm của Quả đất (bên trong, trên mặt vật lý và không gian ngoài của Quả đất). Do định vị Ellipsoid trong lòng Quả đất và thế chuẩn không trùng với thế thực, nên mặt Ellipsoid cắt vô số mặt đẳng thế thực trong trường trọng lực thực của Quả đất, tức mỗi điểm nằm trên mặt Ellipsoid (đồng thời nằm trong lòng Quả đất) đều có thế thực $W$ riêng rẽ. Khi đó điểm $\mathrm{m}_{0}$ trên mặt Ellipsoid (xem hinh 1) có thế thực $W=W_{m_{0}}$ và độ cao Geoid được tính trong trường trọng lực thực theo công thức:

$$
\bar{\zeta}_{M}=\frac{W_{m_{0}}-W_{0}}{g_{m}}
$$

Trong khi đó độ cao Quasigeoid $\zeta_{M}$. được tính trong trường trọng lực chuẩn (lý thuyết) của Quả đất. Gọi thế chuẩn của điểm $\mathrm{m}$ trên mặt Quasigeoid (là hình chiếu của điểm $\mathrm{M}$ lên mặt Quasigeoid) trong trường trọng lực chuẩn bằng $U=U_{m}$. Khi đó độ cao Quasigeoid của 


\section{Mghiên cúu - Uíng dụng}

điểm $\mathrm{M}$ trong trường trọng lực chuẩn được xác định theo công thức:

$$
\zeta_{M}=\frac{U_{0}-U_{m}}{\gamma_{m}},
$$

còn độ cao chuẩn của điểm $\mathrm{M}$ có thể biểu diễn dưới dạng sau:

$$
H_{M}^{\gamma}=\frac{W_{0}-W_{M}}{\gamma_{m}}=\frac{U_{m}-U_{M}}{\gamma_{m}} .
$$

Dị thường độ cao được tính theo công thức (3) và độ cao Quasigeoid được tính theo công thức (7) có giá trị bằng nhau. Do mặt Geoid không trù̀ng với mặt Quasigeoid (trên lục địa), thế chuẩn và gia tốc lực trọng trường chuẩn không bằng thế thực và gia tốc lực trọng trường thực tương ứng, nên độ cao Geoid (6) và độ cao Quasigeoid (7) không bằng nhau. Nhờ điều này chúng ta mới giải thích được sự khác nhau về giá trị giữa độ cao chính và độ cao chuẩn. Ngoài ra từ công thức (6) chúng ta thấy rằng do không thể xác định được thế thực $W=W_{m_{0}}$ tại điểm $\mathrm{m}_{0}$ trên mặt Ellipsoid (và nằm trong lòng Quả đất) và không thể xác định được đại lượng $\mathrm{g}_{\mathrm{m}}$, nên độ cao Geoid không xác định được từ các kết quả đo thuỷ chuẩn trên mặt vật lý của Quả đất. Do đó trong tài liệu $[9, \operatorname{trg}$. 346] khẳng định "độ cao Geoid... như các nghiên cứu chính thức đã chỉ ra không thể tính chính xác", trong tài liệu [6, trg. 62] nêu rõ "các độ cao chính không xác định, sự không xác định được chứa ngay cả trong các độ cao Geoid trên Ellipsoid quy chiếu".

Từ các công thức (5) và (6) chúng ta suy ra công thức tính độ cao trắc địa $\mathrm{H}_{\mathrm{M}}$ của điểm $\mathrm{M}$ trong trường trọng lực thực của Quả đất:

$$
H_{M}=\frac{W_{m_{0}}-W_{M}}{g_{m}}
$$

Với mục đích làm rõ khái niệm về mặt Quasigeoid, trước tiên chúng ta khẳng định này: Mặt Quasigeoid không phải là mặt vật lý tồn tại trong trường trọng lực thực của Quả đất (trên các lục địa). Như vậy chúng ta có khál niệm về mặt Quasigeoid: Mặt Quasigeoid chỉ là hinh ảnh của mặt Geoid với thế thực $W=W_{0}$ trong trường trọng lực chuẩn (lý thuyết) của Quả đất và nhận được tử phép ánh xạ (phép chuyển) mặt Geoid này từ trong trường trọng lực thực của Quả đất về trường trọng lực chuẩn của Quả đất.

Điều này cũng dễ hiểu bởi vì để xác định độ cao chuẩn chúng ta phải chuyển chênh cao đo về chênh cao chuẩn nhờ số cải chính Molodenskii M.X. (tức chuyển chênh cao đo trong trường trọng lực thực của Quả đất về trường trọng lực chuẩn của Quả đất). Điều này cũng giống việc chuyển các trị đo trên mặt vật lý của Quả đất về mặt Ellipsoid hoặc về mặt phẳng trong lưới chiếu Gauss - Kruger (UTM) là các mặt toán học để xử lý toán học các trị đo trong các hệ tọa độ Ellipsoid hoặc hệ tọa độ phẳng. Như vậy cả độ cao chuẩn và dị thường độ cao (hay độ cao Quasigeoid) đều là những đại lượng được xác định trong trọng trường chuẩn (lý thuyết) của Quả đất dựa vào các trị đo thuỷ chuẩn, trọng lực trên mặt vật lý của Quả đất. Điều này cũng giống như việc xác định tọa độ phẳng của các điểm đo trên mặt vật lý của Quả đất nhờ việc bình sai mạng lưới trắc địa trên mặt phẳng của trong lưới chiếu Gauss - Kruger (UTM), chúng ta thực chất nhận được các tọa độ bình sai không phải của bản thân các điểm này, mà là của các hình chiếu của chúng trên mặt phẳng của trong lưới chiếu Gauss - Kruger (UTM). 


\section{Dahiên cuíu - Oíng dụng}

Khái niệm nêu trên giúp chúng ta tránh được sai lầm "trộn lẫn" trường trọng lực thực của Quả đất và trường trọng lực chuẩn của Quả đất để giải quyết bài toán xác định độ cao Geoid và dị thường độ cao và thiết lập mối liên hệ giữa mặt Quasigeoid với mặt Geoid với thế thực $W=W_{0}$ gần với mặt nước biển trung bình không nhiễu trên các biển và đại dương trong việc giải quyết bài toán hoàn thiện hệ độ cao quốc gia. Để chứng minh khái niệm về mặt Quasigeoid nêu trên chúng ta làm sẽ giải quyết các vấn đề được trình bày dưới đây.

\section{Vấn dể 1: Mặt Quasigeoid không trùng với mặt Geoid trên các lục dịa}

Vấn đề này đã được nêu trong nhiều tài liệu về Trắc địa cao cấp, nhưng không có các chứng minh. Từ các công thức (2) và (5) chúng ta có quan hệ

$$
W_{0}-W_{M}=g_{m} \cdot H_{M}^{\prime}=\gamma_{m} \cdot H_{M}^{\gamma} .
$$

Từ đây chúng ta có hiệu của độ cao chính và độ cao chuẩn:

$$
\delta H=H_{M}^{\gamma}-H_{M}^{\mu}=\frac{g_{m}-\gamma_{m}}{g_{m}} \cdot H_{M}^{\mu} .
$$

Như vậy sự khác nhau giữa độ cao chính (trong trường trọng lực thực của Quả đất) và độ cao chuẩn (trong trường trọng lực chuẩn của Quả đất) được gây ra do sự khác nhau giữa gia tốc lực trọng trường thực $\mathrm{g}$ và gia tốc lực trọng trường chuẩn $\gamma$. Do trên các lục địa độ cao chính $H_{M}^{\dot{*}}$ là khoảng cách giữa thế thực $\mathrm{W}=\mathrm{W}_{0}$ và thế thực $\mathrm{W}=\mathrm{W}_{\mathrm{M}}$ (đoạn $\mathrm{Mm}$ ' trên hình 1) và khác với độ cao chuẩn $H_{M}^{\gamma}$ một đại lượng $\delta \mathrm{H}$ khác 0 , nên khi đặt ngược khi đặt ngược từ điểm $\mathrm{M}$ trên mặt vật lý của Quả đất theo đường vuông góc $\mathrm{Mm}_{0}$ một đoạn bằng chúng ta nhận được điểm $\mathrm{m}$ không nằm trên mặt Geoid $\mathrm{W}=\mathrm{W}_{0}$, mà nằm trên mặt Quasigeoid (xem hinh 1).

Vậy vấn đề mặt Quasigeoid nên hiểu như thế nào?. Vấn đề là trước đây khi biểu diễn mặt Geoid với thế thực $W=W_{0}$ và mặt Ellipsoid với thế chuẩn $U=U_{0}$ như trên hình vẽ, chúng ta coi chúng là các mặt trong một trường trọng lực thống nhất, không phân biệt sự khác nhau giữa trường trọng lực thực của Quả đất và trường trọng lực chuẩn của Quả đất. Thực ra độ cao chính, độ cao Geoid và độ cao chuẩn, độ cao Quasigeoid được xác định trong các "hệ quy chiếu khác nhau". Do quỹ tích của mặt Geoid với thế thực $W=W_{0}$ trong trường trọng lực thực của Quả đất thay đổi rất phức tạp, không phải là một mặt đều như mật đẳng thế chuẩn, nên quỹ tích của hình ảnh của mặt đẳng thế thực $W=W_{0}$ trong trường lực trọng trường chuẩn cuả Quả đất không thể là mặt đẳng thế chuẩn, mà chỉ là một mặt toán học được gọi là mặt Quasigeoid.

Từ quan hệ (10) suy ra quan hệ giữa độ cao chuẩn và độ cao chính

$$
H_{M}^{\gamma}=H_{M}^{g}+\frac{g_{m}-\gamma_{m}}{\gamma_{m}} \cdot H_{M}^{g} .
$$

Đây là công thức ánh xạ (chuyển) độ cao chính từ trường trọng lực thực của Quả đất về độ cao chuẩn trong trường trọng lực chuẩn của Quả đất.

Từ đây chúng ta có công thức ánh xạ (chuyển) độ cao Geoid từ trường trọng lực thực của Quả đất về dị thường độ cao (độ cao Quasigeoid) trong trường trọng lực chuẩn của Quả đất : 


\section{Mghiên cứu - Tíng dung}

$$
\zeta_{M}=\bar{\zeta}_{M}-\frac{g_{m}-\gamma_{m}}{\gamma_{m}} \cdot H_{M}^{p}
$$

Khi biết độ cao Quasigeoid $\zeta_{\mathrm{M}}$ chúng ta sẽ xác định được thế chuẩn $\mathrm{U}$ của điểm $\mathrm{m}$ trên mặt Quasigeoid (là hình chiếu của điểm $\mathrm{M}$ theo đường $\mathrm{Mm}_{0}$ lên mặt Quasigeoid trong trường trọng lực chuẩn của Quả đất) theo công thức:

$$
U_{m}=U_{0}-\gamma_{m} \cdot \zeta_{M} \text {. }
$$

Vấn dề 2: Chuyển mặt Geoid với thế thục $W=W_{0}$ từ trường trọng lục thục của Quả dất về mặt Quasigeoid trong trường trọng lực chuẩn của Quả đất

Từ công thức (11) chúng ta có quan hệ giữa dị thường độ cao và độ cao Geoid như sau:

$$
\zeta_{M}=\frac{g_{m}}{\gamma_{m}} \cdot \bar{\zeta}_{M}-\frac{g_{m}-\gamma_{m}}{\gamma_{m}} \cdot H,
$$

hay

$$
\gamma_{m} \cdot \zeta_{M}=g_{m} \cdot \bar{\zeta}_{M}-\left(g_{m}-\gamma_{m}\right) \cdot H_{M} .
$$

ở đây $\mathrm{H}_{\mathrm{M}}$ - độ cao trắc địa.

Từ công thức (12) lưu ý các công thức (6), (7), (9) và công thức tính độ cao trắc địa $H_{M}=\frac{U_{0}-U_{M}}{\gamma_{m}}$ chúng ta có các công thức sau

hay

$$
\begin{aligned}
& U_{m}=W_{0}+\left(U_{M}-W_{m_{0}}\right)+g_{m} \cdot H_{M}, \\
& W_{m_{0}}=W_{M}+g_{m} \cdot H_{M},
\end{aligned}
$$

$$
U_{m}=W_{0}+\left(U_{M}-W_{M}\right)=W_{0}-T_{M},
$$

ở đây $T_{M}=W_{M}-U_{M}$ - thế nhiễu tại điểm $M$ trên mặt vật lý của Quả đất.

Công thức (13) biểu diễn phép ánh xạ (phép chuyển) thế thực $W=W_{0}$ của các điểm nằm trên mặt Geoid $W=W_{0}$ trong trường trọng lực thực của Quả đất về các điểm tương ứng trên mặt Quasigeoid (là hình chiếu của các điểm trên mặt vật lý của Quả đất theo đường $\mathrm{Mm}_{0}$ lên mặt Quasigeoid) trong trường trọng lực chuẩn của Quả đất. Công thức (13) có thể suy ra từ công thức (8).

Như vậy sự khác nhau của thế chuẩn $U$ của điểm $\mathrm{m}$ (là hình chiếu của điểm $\mathrm{M}$ trên mặt vật lý của Quả đất theo đường $\mathrm{Mm}_{0}$ lên mặt Quasigeoid) trên mặt Quasigeoid trong trường trọng lực chuẩn của Quả đất so với thế thực $W=W_{0}$ của điểm $m^{\prime}$ (là hình chiếu của điểm $M$ trên mặt vật lý của Quả đất theo đường $M_{0}$ lên mặt Geoid với thế thực $W=W_{0}$ ) trên mặt Geoid với thế thực $W=W_{0}$ trong trường trọng lực thực của $Q$ uả đất được gây ra bởi sự tồn tại thế nhiễu $T_{M}$ tại điểm $M$ trên mặt vật lý của Quả đất. Điều này có nghĩa là các điểm nằm trên mặt Quasigeoid trong trường trọng lực chuẩn của Quả đất có các thế chuẩn $U$ khác nhau, tức mặt Quasigeoid không phải là mặt đẳng thế chuẩn trong trường trọng lực 


\section{Mghiên cứu - Oíng dụng}

chuẩn của Quả đất, mà chỉ là một mặt toán học trong trường trọng lực này.

Việc coi mặt Quasigeoid là hình ảnh của mặt Geoid với thế thực $W=W_{0}$ làm cho mặt này vừa có ý nghĩa vật lý vừa có ý nghĩa hình học: nó không còn là sản phẩm của việc xác định độ cao chuẩn của các điểm trên mặt vật lý của Quả đất như đã nêu trong [4], mà nó là quỹ tích của các điểm trong trường trọng lực chuẩn có thế chuẩn $U$ được xác định theo công thức (13) và có mối liên hệ chặt chẽ̃ với mặt Geoid với thế thực $W=W_{0}$. Điều kiện (1) của Molodenskii M.X. được xác định tương ứng với mặt Telluroid. Với cách tiếp cận khái niệm về Quasigeoid nêu trên, dựa trên công thức (13) chúng ta biểu diễn điều kiện (1) tương ứng với mặt Quasigeoid như sau:

$$
C_{M}=W_{0}-W_{M}=U_{m}-U_{M} \text {. }
$$

Việc chọn mặt Geoid với thế thực $W=W_{0}$ sẽ được xem xét trong vấn đề 5 ở dưới đây.

Vân để 3: Quan hệ giũa mặt Geoid $W=W_{0}$ và mặt Quasigeoid tại điểm gốc hệ độ cao

Giả sử độ cao chuẩn $H_{N}^{\gamma}$ của điểm $\mathrm{M}$ trên mặt vật lý của Quả đất bằng 0 . Khi đó từ công thức (8) suy ra:

$$
\begin{aligned}
& W_{M}=W_{0}, \\
& U_{M}=U_{m} .
\end{aligned}
$$

Các biểu thức trên cho thấy rằng với điều kiện được đặt ra, điểm $\mathrm{M}$ vừa nằm trên mặt Geoid với thế thực $W=W_{0}$, vừa nằm trên mặt Quasigeoid (thế chuẩn $U_{M}$ tại điểm này bằng thế chuẩn $U_{m}$ của điểm $m$ trên mặt Quasigeoid, thêm vào đó điểm $m$ là hình chiếu của điểm $\mathrm{M}$ theo đường $\mathrm{Mm}_{0}$ lên mặt Quasigeoid). Từ công thức (5) chúng ta suy được ra rằng tại điểm $\mathrm{M}$ độ cao chính $H_{N \prime}^{g}=0$. Như vậy điểm $\mathrm{M}$ đóng vai trò của điểm gốc hệ độ cao quốc gia.

Những điều chứng minh ở trên cho thấy rằng tại điểm gốc $\mathrm{O}$ của hê độ cao quốc gia (xem hình 1) mặt Quasigeoid trùng với mặt Geoid. Điều này đã được khẳng định trong các tài liệu về trắc địa cao cấp, ví dụ [6]. Như vậy tại điểm gốc $O$ mặt Geoid với thế thực $W=$ $W_{0}$ đã ánh xạ vào chinh minh khi chuyển về trường trọng lực chuẩn của Quả đất.

Về mặt lý thuyết tại điểm $\mathrm{O}$ độ cao trắc địa $\mathrm{H}_{0}$, độ cao Geoid $\bar{\zeta}_{0}$, và độ cao Quasigeoid $\zeta_{0}$ bằng nhau. Tuy nhiên như đã trình bày ở phần trên, độ cao Geoid $\bar{\zeta}_{0}$ được tính trong trường trọng lực thực của Quả đất không bằng độ cao Quasigeoid $\zeta_{0}$ được tính trong trường trọng lực chuẩn của Quả đất do hai trường này khác nhau. Chúng ta xem xét vấn đề này.

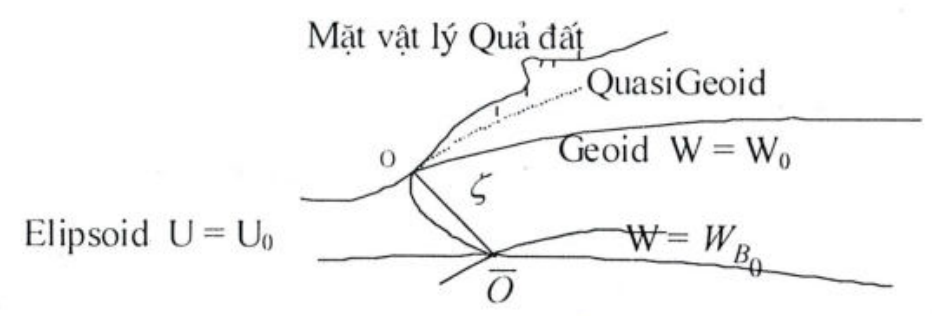

Hinh 2: Điểm gốc O của hệ độ cao 
Trên hình 2 điểm $\bar{O}$ nằm trên mặt Ellipsoid với thế chuẩn $U=\cup_{0}$ và là hình chiếu của điểm $\mathrm{O}$ theo đường vuông góc $O \bar{O}$ xuống mặt Ellipsoid. Do điểm $\bar{O}$ nằm trên mặt Ellipsoid, đồng thời năm trong lòng Quả đất, nên thế thực của trường trọng lực thực của Quả đất tại điểm này bằng $W_{0}$.

Từ các công thức xác định độ cao Geoid (6) và độ cao Quasigeoid (7), đối với điểm O chúng ta có các quan hệ sau:

$$
\begin{aligned}
& W_{0}=W_{0}-g_{m} \cdot \bar{\zeta}_{0}, \\
& \bar{U}_{0}=U_{0}-\gamma_{m} \cdot \zeta_{0},
\end{aligned}
$$

ở đây $\bar{U}_{0}$ - thế chuẩn tại điểm $\mathrm{O}$.

Lấy hiệu hai phương trình trên chúng ta có:

$$
T_{O}=W_{0}-\bar{U}_{0}=\left(W_{\bar{O}}-U_{0}\right)-g_{m} \bar{\zeta}_{0}+\gamma_{m} \cdot \zeta_{0}=T_{\bar{O}}-g_{m} \bar{\zeta}_{0}+\gamma_{m} \cdot \zeta_{0} \text {. }
$$

ở đây $T_{0}$ - thế nhiễu tại điểm $O, \quad T_{\bar{O}}$ - thế nhiễu tại điểm $\bar{O}$ trên mặt Ellipsoid.

Biến đổi công thức (14) chủng ta nhận được công thức:

$$
\bar{\zeta}_{0}-\zeta_{0}=\frac{T_{\overline{0}}-T_{0}}{\gamma_{m}}-\frac{g_{m}-\gamma_{m}}{\gamma_{m}} \cdot \bar{\zeta}_{0}
$$

Thành phần thứ hai ở vế phải của công thức (15) khá nhỏ. Với hiệu $g_{m}-\gamma_{m}=100 \mathrm{mGal}$, $\bar{\zeta}=30 \mathrm{~m}$, thành phần này chỉ ở mức $2 \mathrm{~mm}$. Như vậy sự khác nhau giữa độ cao Quasigeoid $\zeta_{0}$ và độ cao Geoid $\bar{\zeta}_{0}$ tại điểm gốc $O$ của hệ độ cao chủ yếu do sự tồn tại của các thế nhiễu ở chính điểm $O$ và điểm $\bar{O}$ (điểm $\bar{O}$ là hình chiếu của điểm $O$ lên mặt Ellipsoid). Trong thực tế mặt Geoid với thế thực $W=W_{0}$ rất gần với mặt nước biển trung bình không nhiễu trên các biển và đại dương. Các Ellipsoid hiện đại được xác định tương ứng với mặt Geoid này (mặt Ellipsoid gần nhất với mặt Geoid này) và thế thực $W_{0}$ được xác định nhờ phương pháp đo cao vệ tinh (altimetry) và được nhận làm thế chuẩn $U_{0}$ của các Ellipsoid. Ngoài ra khi xây dựng hệ tọa độ quốc gia luôn yêu cầu định vị Ellipsoid sát nhất với mặt Geoid trong phạm vi lãnh thổ quốc gia. Tất cả những điều nêu trên đảm bảo rằng điểm gốc $\mathrm{O}$ của hệ độ cao nằm trên mặt Geoid $W=W_{0}$ sẽ rất gần với mặt Ellipsoid. Điều này cho phép chấp nhận sự chênh nhau nhỏ bỏ qua giữa thế nhiễu $T_{0}$ tại điểm $O$ và thế nhiễu $T_{\bar{O}}$ tại điểm trên mặt Ellipsoid. Khi đó thành phần thứ hai ở vế phảl của biểu thức (15) được coi nhỏ bỏ qua và chúng ta lúc này chấp nhận điều kiện $\mathrm{H}_{0}=\bar{\zeta}_{0}=\zeta_{0}$.

\section{Vấn đề 4: Quan hệ giữa mặt Geoid $W=W_{0}$ và mặt Quasigeoid trên biển và các đại dương}

Các số liệu nghiên cứu hiện đại cho thấy mặt nước biển trung bình trên các biển và đại dương không phải là mặt đẳng thế $[2,6]$. Do đó mặt nước biển trung bình trên các biển và đại dương không trùng với Geoid có thế thực $W=W_{0}$. Vì lý do này mặt nước biển trung bình trên các biển và đại dương được gọi là mặt địa hình biển (Sea Topography Surface) (xem $[6,11])$ và các điểm trên mặt địa hình biển có độ cao chính khác 0 so với mặt Geoid với thế 
thực $\mathrm{W}=\mathrm{W}_{0}$. Từ quan hệ giữa độ cao chính và độ cao chuẩn $H^{\prime}=\frac{y_{m}}{\gamma_{*}} \cdot H^{*}$ chúng ta thấy rằng các điểm trên mặt địa hình biển có độ cao chuẩn khác 0 so với mặ̆t Quasigeoid. Như vậy việc coi độ cao chuẩn của các điểm trên các biển và đại dương bằng 0 là không chính xác. Từ đây đặt ra yêu cầu xây dựng bản đồ địa hình biển. Phương pháp chủ yếu để xác định mặt địa hình biển hiện nay được thực hiện bằng phương pháp đo cao vệ tinh (altimetry) nhờ các hệ thống vệ tinh ERS - 1 và TOPEX/POSEIDON [11] với độ chính xác ở mức $\mathrm{cm}$.

Do mặt nước biển trung bình trên các biển và đại dương chênh với mặt Geoid ở mức $1 \mathrm{~m}$ [6], nên khi nhận độ cao chính của các điểm trên mặt địa hình biển bằng $1 \mathrm{~m}$ và với giá trị trung bình của dị thường trọng lực trên Quả đất $g_{m}-\gamma_{m}=40 \mathrm{mGal}$ từ công thức $(10)$ suy ra $\delta H=0,04 \mathrm{~mm}$. Như vậy trên biển và các đại dương sự chênh giữa độ cao chính và độ cao chuẩn của các điểm trên mặt địa hình biển nhỏ bỏ qua. Vì lỳ do này mặt Quasigeoid được coi là trùng với mặt Geoid trên các biển và đại dương. Với kết luận này chúng ta thấy rằng Mặt Quasigeoid là mặt toán học trên các lục địa và là mặt đẳng thế (mặt vật lý) trên các biển và đại dương. Điểu này có nghĩa là trên các biển và đại dương mặt Quasigeoid nhận được từ phép ánh xạ vào chính minh của mặt Geoid với thế thực $W=W_{0}$. Với kết luận này, từ công thức (13) chúng ta thấy rằng thế nhiều $T_{M}$ của các điểm nằm trên mặt địa hình biển được coi bằng 0 . Điều này có thể được giải thích bởi các lý do sau:

- Thế thực $W=W_{0}$ của mặt Geoid gần nhất với mặt nước biển trung bình trên các biển và đại dương được xác định nhờ phương pháp đo cao vệ tinh (altimetry). Kích thước của Ellipsoid hiện đại được xác định phù hợp nhất với mặt Geoid này và thế chuẩn $\cup_{0}$ trên mặt Ellipsoid được nhận bằng thế thực $W_{0}$, tức $U_{0}=W_{0}$;

- Đối với điểm $M$ nằm trên mặt địa hình biển, thế thực $W_{M}$ và thế chuẩn $U_{M}$ của nó được xác định theo các công thức sau:

$$
\begin{aligned}
& W_{M}=W_{O}-g_{m} \cdot H_{M}^{g} . \\
& U_{M}=U_{0}-\gamma_{m} \cdot H_{M}^{\gamma} .
\end{aligned}
$$

Do độ cao chính $H_{M}^{\mu}$ và độ cao chuẩn $H_{M}^{\gamma}$ của điểm $\mathrm{M}$ nằm trên mặt địa hình biển bằng nhau, nền từ các công thức (5) và (8) chúng ta có thể coi các giá trị trung bình của gia tốc lực trọng trường thực $\mathrm{g}_{\mathrm{m}}$ và gia tốc lực trong trường chuẩn $\gamma_{m}$ là bằng nhau.

Với các điều kiện nêu trên từ công thức (16) suy ra $W_{M}=U_{M}$, tức thế nhiễu của điểm $M$ nằm trên mặt địa hình biển bằng 0 .

\section{Vấn để 5: Chọn mặt Geoid với thế thực $W=W_{0}$}

Như đã trình bày ở trên, mặt Geoid với thế thực $W=W_{0}$ trên các biển và đại dương được xác định nhờ phương pháp đọ cao vệ tinh (altimetry) và rất gần với mặt nước biển trung bình không nhiễu trên các biển và đại dương. Thế thực $W_{0}$ xác định được đã được chọn làm thế chuẩn $U_{0}$ của mặt các Ellipsoid hiện đại. Theo tài liệu [10], Ellipsoid phù hợp nhất với Geoid $W=W_{0}$ có bán kính bán trục lớn $a=6378136,6 \mathrm{~m}$ và thế thực $W_{0}=62636856,0$ $m^{2} \cdot s^{-2}$ rất gần với thế chuẩn $U_{0}=62636861,074 \mathrm{~m}^{2} \cdot \mathrm{s}^{-2}$ của Ellipsoid $\mathrm{PZ}-90$ và của Ellipsoid WGS-84 bằng $U_{0}=62636860,648 \mathrm{~m}^{2} / \mathrm{s}^{2}$, trong khi đó thế chuẩn của Ellipsoid WGS-80 bằng $U_{0}=62636874,435 \mathrm{~m}^{2} / \mathrm{s}^{2}$. Do đó để xây dựng hệ độ cao chuẩn hiện đại đảm bảo thống nhất việc xác định độ cao trên đất liền và độ sâu địa hình đáy biển, địa hình mặt biển 
trong phạm vi một quốc gia hoặc một khu vực rộng hơn, trong các tài liệu $[12,13]$ đã đề xuất sử dụng mặt Geoid với thế thực $W=W_{0}=U_{0}$ là mặt khởi tính. Trong tài liệu [2] đã đề xuất phương pháp chuyển hệ độ cao chuẩn được xác định từ mặt nước biển trung bình tại một trạm nghiệm triều về mặt Geoid với thế thực $\mathrm{W}=\mathrm{W}_{0}=\mathrm{U}_{0}$. Tuy nhiên do trường trọng lực thực của Quả đất không trùng với trường trọng lực chuẩn của Quả đất và sự phân bố vật chất rất phức tạp trong lòng Quả đất làm cho sự phân bố của các mặt đẳng thế thực rất phức tạp, nên mặt Geoid với thế thực $W=U_{0}$ không trùng với mặt Ellipsoid với thế chuẩn $U=U_{0}$. Việc chọn mặt Geoid như trên làm cho điều kiện (1) của Molodenskii M.X. trở nên xác định và nhất quán khi xây dựng hệ độ cao chuẩn thống nhất cho các khu vực khác nhau trên thế giới.

Nếu chọn thế thực $W_{0}$ của mặt Geoid bằng thế chuẩn $U_{0}$ của mặt Ellipsoid, thì thay $W_{0}$ $=U_{0}$ vào công thức (13) và lưu ý công thức tính độ cao Quasigeoid (7) và dị thường độ cao (4) chúng ta nhận được công thức tính cả độ cao Quasigeoid lẫn dị thường độ cao ở dạng

Trong trường hợp này, từ điều kiện (1) suy ra thế chuẩn $U_{N}$ của các điểm trên mặt Telluroid bằng thế thực $W_{M}$ của các điểm $M$ trên mặt vật lý của Quả đất và như đã chỉ ra trong tài liệu [3], mặt Telluroid là hình ảnh của mặt vật lý của Quả đất trong trường trọng lực chuẩn. Tuy nhiên mặt Telluroid không trùng với mặt vật lý của Quả đất do sự khác nhau của trường trọng lực thực và trường trọng lực chuẩn của Quả đất. Chính điều nêu trên giải thích sự tồn tại của dị thường độ cao (và độ cao Quasigeoid) trong trường hợp đang xem xét.

\section{Kết luận}

Việc coi măt Quasigeoid là hình ảnh của mặt Geoid với thế thực $W=W_{0}$ trong trường trọng lực chuẩn của Quả đất cho phép không những làm rõ mối quan hệ giữa hai mặt này và xác định được các ý nghĩa vật lý và hình học của mặt Quasigeoid, mà còn xác định rõ ràng sự khác nhau về mặt hình học gia các đại lượng như độ cao Geoid, dị thường độ cao và độ cao Quasigeoid cửng như các mối quan hệ giữa chúng. Không những thế chúng ta tránh được những sai lầm cố hữu khi giải thích các đại lượng nêu trên trong sự trộn lẫn trường trọng trường thực của Quả đất với trường trọng lực chuẩn của Quả đất. Với quan niệm về mặt Quasigeoid như đã nêu ở trên, chúng ta xây dựng được công thức (7) để xác định độ cao Quasigeoid và biểu diễn được điều kiện (1) của Molodenskii M.X. dưới dạng điều kiện (13a) khi gắn với mặt Quasigeoid. Từ công thức (8) việc xác định độ cao chuẩn được xây dựng khi gắn với mặt Quasigeoid, chúng ta dễ dàng chứng minh được các mặt Quasigeoid và mặt Geoid với thế thực $W=W_{0}$ trùng nhau tai điểm gốc hệ độ cao và trên các biển và đại dương. Công thức (13) cho thấy khi thay đổi mặt Geoid với thế thực $W=$ $W_{0}$, mặt Quasigeoid sẽ thay đổi theo. Điều này đòi hỏi phải có sự hiệu chỉnh lại các độ cao chuẩn đã có từ trước cho phù hợp với mặt Quasigeoid mới. Do mặt Quasigeoid trùng với mặt Geoid với thế thực $W=W_{0}$ trên các biển và đại dương, nên để hiện đại hoá hệ độ cao chuẩn quốc gia hoặc khu vực trong giai đoạn hiện nay chủ yếu phụ thuộc vào việc lựa chọn mặt Geoid với thế thực $W=W_{0}$. Mặt Geoid với thế thực $W=W_{0}$ hiện đại nhất hiện nay có bán kính bán trục lớn $\mathrm{a}=6378136,6 \mathrm{~m}$ và thế thực $\mathrm{W}_{0}=62636856,0 \mathrm{~m}^{2} \cdot \mathrm{s}^{2}$. Ngoài ra do độ cao chuẩn trên mắt địa hình biển khác 0 , nên việc thành lập bản đồ địa hình biển cần quan tâm ở Việt Nam để hiện đại hoá công tác đo sâu địa hình đáy biển và hiển thị các hiện tượng vật lý diển ra trên mặt biển. $O$

\section{TÀI LIẸU THAM KHẢO}

[1]. Hà Minh Hoà. (2008). Điểm gốc hệ tọa độ quốc gia - vai trò và ý nghĩa của nó trong quá trình phát triển hệ tọa độ quốc gia. Tạp chí Địa chính, số 1, tháng 2/2008, trg. 6-13. 


\section{Mghiên cuím - Míng dụng}

[2]. Hà Minh Hoà. (2007). Giải quyết một số vấn đề liên quan đến việc chuyển hệ độ cao được xác định từ mặt nước biển trung binh ở trạm thuỷ triều về mặt Quasigeoid toàn cầu. Tạp chí Địa chính, số 2, tháng 4/2007, trg. 3-11.

[3]. Hà Minh Hoà. (2007). Luận chứng về việc chọn mặt đẳng thế với thế $W_{0}$ bằng thế chuẩn $\bigcup_{0}$ trên mặt Ellipsoid làm mặt khởi tính cho hệ độ cao quốc gia hiện đại. Tạp chí Địa chính, số 5 , tháng 10/2007, trg. 10-17.

[4]. Ogorodova L.V. (2009). Về sự liên hệ của độ cao Geoid và Kvazigeoid với các dị thường độ cao.IZV.VUZOV. Geodezia i Aerophotoxemka, No3, 2009. Trg. 12-16. (Tiếng $\mathrm{Nga})$.

[5]. Ogorodova L.V., Simberev B.P., luzephovich A.P. (1975). Trọng lực. Matxcơva, Nedra, 325 trg. (Tiếng Nga).

[6]. Pellinen B.P. (1978). Trắc địa cao cấp (trắc địa lý thuyết). Matxcơva, Nedra, 264 trg. (Tiếng Nga).

[7]. Makarov N.P. (1959). Môn Trọng lực trắc địa. BIA, Matxcơva, 358 trg. (Tiếng Nga). $\mathrm{Nga})$

[8]. Simberev B.P. (1975). Lý thuyết hình dạng Quả đất.Matxcơva, Nedra, 432 trg. (Tiếng

[9]. Zakatov P.X. (1964). Môn Trắc địa cao cấp. Matxcơva, Nedra, 504 trg. (Tiếng Nga).

[10]. Groten E. (1999). Report of the IAG. Special Commision SC3, Fundamental Constants, XXII IAG General Assembly.

[11]. Zhang K.F., Featherstone W.E., Kirby J.F. (1996). Towards a new gravimetric Geoid of Australia. Technical Papers. 37 th Australia Surveyors Congress. Perth. $13-18$ th, April, 1996, 137 - 148 pp.

[12]. Zalkovskii E. A., Demianov G.V., Brovar B.V., Maiorov A.N., Taranov V.A., lurkina M.I. (1998). Trọng lực và trắc địa vệ tinh hiện đại. Matxcơva, TXNHIIGAiK. 3-11 trg. (Tiếng Nga).

[13]. Demianov G.V. (2004). Thiết lập các nguyên tắc phát triển hệ thống độ cao chuẩn trên cơ sở công nghệ vệ tinh hiện đại. Luận án TSKH. Matxcơva, 147 trg. (Tiếng Nga).O

\section{Summary}

\section{APPROACH TO CONCEPTION OF A QUASIGEOID}

Ass. Prof. Dr.Sc. Ha Minh Hoa

Vietnam Institute of Geodesy and Cartography

Molodenskii M.X. had raised a Quasigeoid surface for making a display of normal height from the Earth physical surface by perpendicur to the Ellipsoid. However in literature of heigh Geodesy there are different explanations about thi surface, even it seems to be only product of normal height definition process on the the Earth physical surface. This scientific report will show that the Quasigeoid is a image of the Geoid with real potencial $W=W_{0}$ in the Earth normal gravitational field and closely related to this Geoid. So we can see a relationship between the Quasigeoid and Geoid on the sea and ocean, and must reconsider a point of view about zero normal height on the sea and ocean. Research results in this article will determine scientific bases for perfection of the state height system. $O$ 